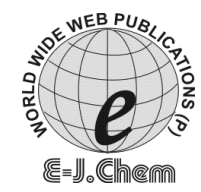

http://www.e-journals.net

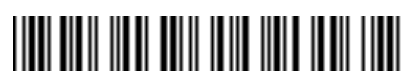

ISSN: 0973-4945; CODEN ECJHAO

E-Journal of Chemistry

Vol. 4, No. 3, pp. 343-349, July 2007

\title{
Density and Comparative Refractive Index Study on Mixing Properties of Binary Liquid Mixtures of Eucalyptol with Hydrocarbons at 303.15, 308.15 and 313.15K
}

\author{
SANGITA SHARMA*, PRAGNESH B. PATEL, \\ RIGNESH S. PATEL and J. J. VORA \\ Department of Chemistry, \\ Hemchandracharya North Gujarat University, \\ Patan - 384265 (Gujarat) India \\ smridhee2000@yahoo.co.in
}

Received 20 November 2006; Accepted 22 December 2006

\begin{abstract}
Density and refractive index have been experimentally determined for binary liquid mixtures of eucalyptol with hydrocarbons (o-xylene, $m$-xylene and toluene) at $303.15 \mathrm{~K}, 308.15 \mathrm{~K}$ and $313.15 \mathrm{~K}$. A comparative study of Lorentz-Lorenz (L-L), Weiner (W), Heller (H), Gladstone-Dale (GD), Arago-Biot (A-B), Eykman (Eyk), Newton (Nw), Eyring-John (E-J) and Oster (Os) relations for determining the refractive index of a liquid has been carried out to test their validity for the three binaries over the entire mole fraction range of eucalyptol at $303.15 \mathrm{~K}, 308.15 \mathrm{~K}$ and $313.15 \mathrm{~K}$. Comparison of various mixing rules has been expressed in terms of average deviation. From the experimentally measured values, refractive index deviations at different temperatures have been computed and fitted to the Redlich-Kister polynomial equation to derive the binary coefficients and standard deviations.
\end{abstract}

Keywords: Density, Refractive index, Binary liquid mixtures and Eucalyptol

\section{Introduction}

Accurate knowledge of thermodynamic mixing properties of binary mixtures has great relevance in theoretical and applied areas of research. These data are needed for design process in chemical, petrochemical and pharmaceutical industries. 
Refractive index and density measurements of binary liquid mixtures are essential for determination of composition of binary mixtures usually for non-ideal mixtures where direct experimental measurements are performed over the entire composition range. Most empirical approach for calculating the excess properties is an attempt to explain non-ideality in terms of specific and non-specific intermolecular interactions. The most widely used rules for predictivity of refractivity in case of binary liquid mixtures are Arago-Biot ${ }^{1}$, Gladstone-Dale ${ }^{2}$, Lorentz-Lorenz ${ }^{3-4}$, Eykman $^{5}$, Weiner ${ }^{6}$, Heller ${ }^{7}$, Newton ${ }^{8}$, Oster ${ }^{9}$ and Eyring-John ${ }^{10}$. Many authors ${ }^{11-19}$ have applied these properties to study the structures, solvent-solute interactions and the solvation behaviour in binary liquid mixtures.

\section{Experimental}

The chemicals used were of A. R. grade. The purity of compounds was checked as per the method given earlier ${ }^{22}$ and results agreed reasonably with corresponding literature values.

Mixtures were prepared by mixing the appropriate volumes of liquids in specially designed ground glass air tight ampules and weighed in single pan balance (Mettler Toledo AB 204 electronic balance) to an accuracy of $\pm 0.0001 \mathrm{gm}$. Preferential evaporation losses of solvent from the mixture were kept to a minimum as evidenced by repeated measurements of physical properties over an interval of 2-3 days during which time no change in physical properties were observed. The possible error in mole fraction is estimated to be around 0.0001 . Density of pure liquids and their binary mixtures in the composition range of 0.0660 to 0.8689 mole fraction increments were measured by using pycnometer having bulb volume of $10 \mathrm{~cm}^{3}$ and capillary with the internal diameter $1 \mathrm{~mm}$ for each measurement. Sufficient time was allowed to attain thermal equilibrium in High Precision Water Bath, Cat No. MSW-274 thermostat, the bath temperature was monitored to $\pm 0.01^{\circ} \mathrm{C}$ with a calibrated thermometer. The reported density at $303.15 \mathrm{~K}, 308.15 \mathrm{~K}$ and $313.15 \mathrm{~K}$ are significant at four figures. An average of triplicate measurements was taken into account and their reproducibility was with in range of \pm 0.00001 .

Refractive index for the sodium D line was measured with a thermostatic Abbe's refractometer, SER. No. 95033 with is error less than 0.0001 units. These data were approximated to four digits of decimal. Water was circulated into the instrument through the thermostatically controlled bath. The refractometer was calibrated using glass test piece of known refractive index supplied with the instrument.

\section{Results and Discussion}

The experimental refractive indexes of eucalyptol with hydrocarbons are presented in Table 1 and the data have been used to evaluate refractive index deviations, via following equation

$$
\mathrm{n}^{\mathrm{E}}=\mathrm{n}_{\mathrm{m}}-\sum \mathrm{x}_{\mathrm{i}} \mathrm{n}_{\mathrm{i}}
$$

Where $\mathrm{x}_{\mathrm{i}}$ and $\mathrm{n}_{\mathrm{i}}$ represent the mole fraction and the refractive index of the $i^{\text {th }}$ component respectively and $n_{m}$ is the refractive index of the binary liquid mixture.

The refractive index deviations were fitted with Redlich-Kister ${ }^{20}$ polynomial equation of the form

$$
\mathrm{n}^{\mathrm{E}}=\mathrm{x}_{1}\left(1-\mathrm{x}_{1}\right) \sum_{\mathrm{i}=0}^{\mathrm{n}} \mathrm{a}_{\mathrm{i}}\left(2 \mathrm{x}_{1}-1\right)_{\mathrm{i}}
$$

where $\mathrm{x}_{1}$ is the mole fraction of the pure component 1 and $\mathrm{a}_{\mathrm{i}}$ are the polynomial coefficients evaluated by fitting the equation to the experimental result with a least squares regression method. The standard deviations, $\sigma$ were calculated using the expression, 


$$
\sigma=\left\{\sum\left(\mathrm{Y}_{\exp }^{\mathrm{E}}-\mathrm{Y}_{\text {fit }}^{\mathrm{E}}\right)^{2} /(\mathrm{n}-\mathrm{p})\right\}^{1 / 2}
$$

where $n$ is the number of measurements. $p$ is the number of coefficients. The values of coefficients, $a_{i}$ and the standard deviations, $\sigma$ are presented in Table 2.

Table 1. Experimental Densities $(\rho)$, Refractive Indexes $\left(\mathrm{n}_{\text {exp }}\right)$ and Excess Refractive Indexes $\left(\mathrm{n}^{\mathrm{E}}\right)$ of binary liquid mixtures of Eucalyptol with Hydrocarbons at 303.15K, 308.15K and 313.15K

\begin{tabular}{|c|c|c|c|c|c|c|c|c|c|}
\hline \multirow[b]{3}{*}{$\mathrm{x}_{1}$} & \multicolumn{9}{|c|}{ Eucalyptol $\left(\mathrm{x}_{1}\right)+o$-Xylene $\left(\mathrm{x}_{2}\right)$} \\
\hline & \multicolumn{3}{|c|}{$303.15 \mathrm{~K}$} & \multicolumn{3}{|c|}{$308.15 \mathrm{~K}$} & \multicolumn{3}{|c|}{$313.15 \mathrm{~K}$} \\
\hline & $\rho\left(\right.$ g.cm $\left.{ }^{-3}\right)$ & $\mathrm{n}_{\exp }$ & $\mathrm{n}^{\mathrm{E}}$ & $\rho\left(\right.$ g.cm $\left.{ }^{-3}\right)$ & $\mathrm{n}_{\exp }$ & $\mathrm{n}^{\mathrm{E}}$ & $\rho\left(\right.$ g.cm $\left.{ }^{-3}\right)$ & $\mathrm{n}_{\exp }$ & $\mathrm{n}^{\mathrm{E}}$ \\
\hline 0.0000 & 0.87151 & 1.5002 & 0.000 & 0.86702 & 1.4991 & 0.000 & 0.86316 & 1.4981 & 0.000 \\
\hline 0.0744 & 0.87572 & 1.4937 & -0.003 & 0.87124 & 1.4925 & -0.003 & 0.86733 & 1.4915 & -0.003 \\
\hline 0.1532 & 0.87995 & 1.4860 & -0.007 & 0.87547 & 1.4848 & -0.007 & 0.87150 & 1.4838 & -0.007 \\
\hline 0.2368 & 0.88422 & 1.4780 & -0.011 & 0.87974 & 1.4766 & -0.011 & 0.87569 & 1.4755 & -0.011 \\
\hline 0.3255 & 0.88854 & 1.4704 & -0.014 & 0.88406 & 1.4688 & -0.015 & 0.87995 & 1.4675 & -0.015 \\
\hline 0.4199 & 0.89292 & 1.4640 & -0.016 & 0.88844 & 1.4619 & -0.017 & 0.88428 & 1.4603 & -0.017 \\
\hline 0.5206 & 0.89738 & 1.4594 & -0.016 & 0.89291 & 1.4566 & -0.017 & 0.88870 & 1.4548 & -0.018 \\
\hline 0.6281 & 0.90191 & 1.4568 & -0.013 & 0.8 & 1.4535 & -0.015 & 0.89323 & 1.4 & -0.016 \\
\hline 0.7433 & 0.90651 & 1.4561 & -0.009 & & & -0.011 & 0.89786 & & -0.012 \\
\hline 0.8669 & 0.91116 & 1.4557 & -0.003 & 0.90682 & 1.4522 & -0.005 & 0.90255 & 1.4497 & -0.006 \\
\hline \multirow[t]{2}{*}{1.0000} & 0.91581 & 1.4523 & 0.000 & 0.91151 & 1.4507 & 0.000 & 0722 & 1.4491 & 0.000 \\
\hline & \multicolumn{9}{|c|}{ Eucalyptol $\left(\mathrm{x}_{1}\right)+m$-Xylene $\left(\mathrm{x}_{2}\right)$} \\
\hline 0.0000 & 0.85561 & 1.4920 & 0.000 & 0.85152 & 1.4912 & 0.000 & 0.84676 & 1.4902 & 0.000 \\
\hline 0.0757 & 0.86135 & 1.4861 & -0.003 & 0.85725 & 1.4852 & -0.003 & 0.85252 & 1.4832 & -0.004 \\
\hline 0.1555 & 0.86716 & 1.4799 & -0.006 & 0.86301 & 1.4784 & -0.006 & 0.85830 & 1.4760 & -0.008 \\
\hline 0.2400 & 0.87302 & 1.4737 & -0.009 & 0.86 & 1.4715 & -0.010 & 413 & 1.4692 & -0.011 \\
\hline 0.3294 & 0.87894 & 1.4681 & -0.011 & 0.87469 & 1.4650 & -0.013 & 0.87003 & 1.4630 & -0.014 \\
\hline 0.4242 & 0.88492 & 1.4632 & -0.012 & 0.88063 & 1.4596 & -0.014 & 0.87600 & 1.4577 & -0.015 \\
\hline 0.5250 & 0.89097 & 1.4595 & -0.012 & 0.88666 & 1.4558 & -0.014 & 0.88208 & 1.4537 & -0.015 \\
\hline 0.6322 & 0.89708 & 1.4570 & -0.010 & 0.89277 & 1.4538 & -0.012 & 0.88825 & 1.4510 & -0.013 \\
\hline 0.7466 & 0.90326 & 1.4557 & -0.007 & 0.89895 & 1.4533 & -0.008 & 0.89452 & 1.4498 & -0.010 \\
\hline 0.8689 & 0.90950 & 1.4547 & -0.003 & 0.90521 & 1.4531 & -0.003 & 0.90086 & 1.4495 & -0.005 \\
\hline \multirow[t]{2}{*}{1.0000} & 0.91581 & 1.4523 & 0.000 & 0.91151 & 1.4507 & 0.000 & 0.90722 & 1.4491 & 0.000 \\
\hline & \multicolumn{9}{|c|}{ Eucalyptol $\left(\mathrm{x}_{1}\right)+$ Toluene $\left(\mathrm{x}_{2}\right)$} \\
\hline 0.0000 & & & & & & & & & \\
\hline 0.0660 & 0.86291 & 1.4834 & -0.005 & 0.85825 & & & & & -0.006 \\
\hline 0.1371 & 0.86842 & 1.4769 & -0.009 & 0.86377 & 1.4736 & -0.010 & 0.85929 & 1.4704 & -0.011 \\
\hline 0.2141 & 0.87403 & 1.4714 & -0.011 & 0.86940 & 1.4679 & -0.013 & 0.86490 & 1.4645 & -0.014 \\
\hline 0.2976 & 0.87974 & 1.4669 & -0.012 & 0.87512 & 1.4635 & -0.014 & 0.87062 & 1.4599 & -0.015 \\
\hline 0.3886 & 0.88554 & 1.4631 & -0.013 & 0.88093 & 1.4601 & -0.014 & 0.87643 & 1.4565 & -0.015 \\
\hline 0.4880 & 0.89141 & 1.4600 & -0.012 & 0.88685 & 1.4575 & -0.013 & 0.88236 & 1.4540 & -0.014 \\
\hline 0.5972 & 0.89736 & 1.4574 & -0.010 & 0.89285 & 1.4553 & -0.011 & 0.88840 & 1.4521 & -0.012 \\
\hline 0.7177 & 0.90339 & 1.4551 & -0.008 & 0.89896 & 1.4533 & -0.008 & 0.89456 & 1.4507 & -0.009 \\
\hline 0.8512 & 0.90952 & 1.4532 & -0.005 & 0.90517 & 1.4516 & -0.005 & 0.90083 & 1.4496 & -0.005 \\
\hline 1.0000 & 0.91581 & 1.4523 & 0.000 & 0.91151 & 1.4507 & 0.000 & 0.90722 & 1.4491 & 0.000 \\
\hline
\end{tabular}

Figure 1 represents the values of refractive index deviations of eucalyptol with hydrocarbons varying with the mole fraction of the first component for the binary mixtures 
at $303.15 \mathrm{~K} . \mathrm{n}^{\mathrm{E}}$ values are negative over the complete mole fraction range for eucalyptol + hydrocarbon binary mixtures indicative of strong intermolecular interactions related to decrease in molar volume and negative enthalpy change on mixing.

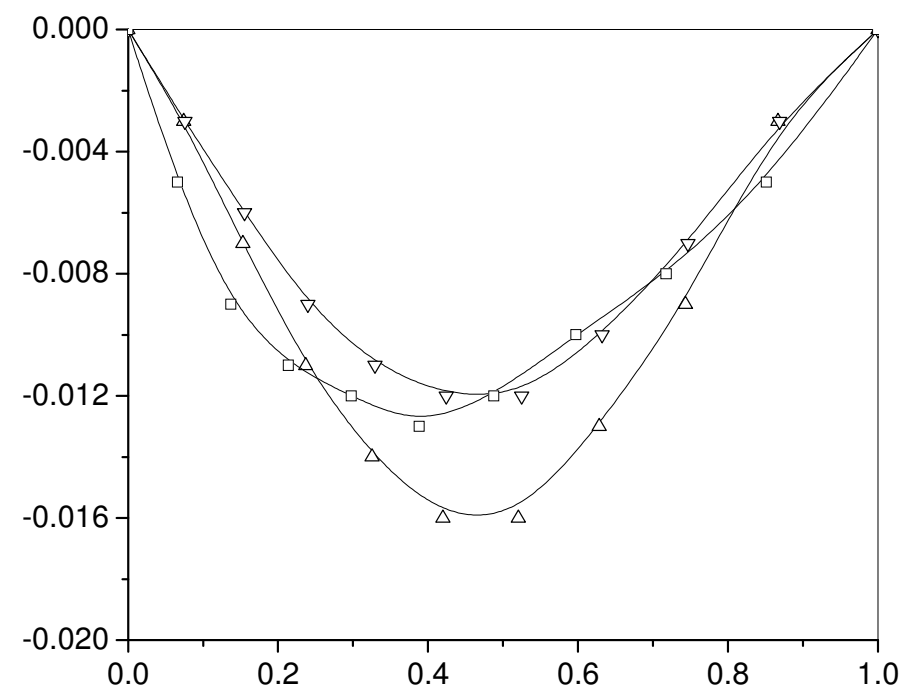

Figure 1. Excess Refractive Index $\left(\mathrm{n}^{\mathrm{E}}\right)$ with mole fraction $\left(\mathrm{x}_{1}\right)$ for Eucalyptol(1)+ $o$-Xylene(2) ( $\Delta)$, Eucalyptol $(1)+m$-Xylene $(2)(\nabla)$, Eucalyptol $(1)+$ Toluene(2) $(\square)$ at $303.15 \mathrm{~K}$.

Following nine equations are used for quantitative determination of refractive indexes of binary mixtures.

Arago-Biot (A-B) : $\quad \mathrm{n}=\mathrm{n}_{4} \phi_{1+} \mathrm{n}_{2} \phi_{2}$

Gladstone-Dale (G-D) : $\mathrm{n}-1=\left(\mathrm{n}_{1}-1\right) \phi_{1}+\left(\mathrm{n}_{2}-1\right) \phi_{2}$

Lorentz-Lorenz (L-L) : $\frac{\mathrm{n}^{2}-1}{\mathrm{n}^{2}+2}=\left(\frac{\mathrm{n}_{1}^{2}-1}{\mathrm{n}_{1}^{2}+2}\right) \phi_{1}+\left(\frac{\mathrm{n}_{2}^{2}-1}{\mathrm{n}_{2}^{2}+2}\right) \phi_{2}$

Eykman (Eyk) : $\frac{n^{2}-1}{n+0.4}=\left(\frac{n_{1}^{2}-1}{n_{1}+0.4}\right) \phi_{1}+\left(\frac{n_{2}^{2}-1}{n_{2}+0.4}\right) \phi_{2}$

Weiner $(W): \frac{n^{2}-n_{1}^{2}}{n^{2}+2 n_{2}^{2}}=\left[\frac{n_{2}^{2}-n_{1}^{2}}{n_{2}^{2}+2 n_{1}^{2}}\right] \phi_{2}$

Heller $(\mathrm{H}): \frac{\mathrm{n}-\mathrm{n}_{1}}{\mathrm{n}_{1}}=\frac{3}{2}\left[\frac{\left(\mathrm{n}_{2} / \mathrm{n}_{1}\right)^{2}-1}{\left(\mathrm{n}_{2} / \mathrm{n}_{1}\right)^{2}+2}\right] \phi_{2}$

Newton (Nw) : $\mathrm{n}^{2}-1=\left(\mathrm{n}_{1}^{2}-1\right) \phi_{1}+\left(\mathrm{n}_{2}^{2}-1\right) \phi_{2}$

Oster (Os) : $\frac{\left(\mathrm{n}^{2}-1\right)\left(2 \mathrm{n}^{2}+1\right)}{\mathrm{n}^{2}}=\frac{\left(\mathrm{n}_{1}^{2}-1\right)\left(2 \mathrm{n}_{1}^{2}+1\right)}{\mathrm{n}_{1}^{2}} \phi_{1}+\frac{\left(\mathrm{n}_{2}^{2}-1\right)\left(2 \mathrm{n}_{2}^{2}+1\right)}{\mathrm{n}_{2}^{2}} \phi_{2}$ 
Eyring and John (E-J) : $\mathrm{n}=\mathrm{n}_{1} \phi_{1}^{2}+2\left(\mathrm{n}_{1} \mathrm{n}_{2}\right)^{1 / 2} \phi_{1} \phi_{2}+\mathrm{n}_{2} \phi_{2}^{2}$

In all these equations,

$$
\begin{gathered}
\mathrm{n}=\text { Refractive index of mixture } \\
\mathrm{n}_{1}=\text { Refractive index of pure component-1 } \\
\mathrm{n}_{2}=\text { Refractive index of pure component-2 } \\
\phi_{1}=\text { Volume fraction of pure component-1 } \\
\phi_{2}=\text { Volume fraction of pure component-2 }
\end{gathered}
$$

Where $\phi_{1}=\mathrm{x}_{1} \mathrm{~V}_{1} / \sum \mathrm{x}_{\mathrm{i}} \mathrm{V}_{\mathrm{i}}$ and $\phi_{2}=\mathrm{x}_{2} \mathrm{~V}_{2} / \sum \mathrm{x}_{\mathrm{i}} \mathrm{V}_{\mathrm{i}}$

Here $\quad \mathrm{x}$ is the mole fraction

$\mathrm{V}_{\mathrm{i}}$ is the molar volume of component $\mathrm{i}$

Table 2. Parameters, $\mathrm{a}_{\mathrm{i}}$ and standard deviation, $\sigma$ for Eucalyptol + Hydrocarbon binary liquid mixtures at $303.15 \mathrm{~K}, 308.15 \mathrm{~K}$ and $313.15 \mathrm{~K}$ for $\mathrm{n}^{\mathrm{E}}$

\begin{tabular}{clccc}
\hline \multicolumn{5}{c}{ Eucalyptol $\left(\mathrm{x}_{1}\right)+o$-Xylene $\left(\mathrm{x}_{2}\right)$} \\
\hline $\mathrm{T} / \mathrm{K}$ & \multicolumn{1}{c}{$\mathrm{a}_{0}$} & $\mathrm{a}_{1}$ & $\mathrm{a}_{2}$ & $\sigma$ \\
\hline 303.15 & -0.065 & 0.017 & 0.048 & 0.000127 \\
308.15 & -0.070 & 0.006 & 0.042 & 0.000123 \\
313.15 & -0.072 & 0.000 & 0.038 & 0.000124 \\
\multicolumn{5}{c}{ Eucalyptol } \\
303.15 & -0.048 & $\left.\mathrm{x}_{1}\right)+m$-Xylene $\left(\mathrm{x}_{2}\right)$ \\
308.15 & -0.013 & 0.023 & 0.000124 \\
313.15 & -0.061 & 0.015 & 0.038 & 0.000127 \\
5 & Eucalyptol $\left(\mathrm{x}_{1}\right)+$ Toluene $\left(\mathrm{x}_{2}\right)$ & 0.000132 \\
303.15 & -0.048 & 0.024 & -0.016 & 0.000133 \\
308.15 & -0.051 & 0.033 & -0.023 & 0.000138 \\
313.15 & -0.056 & 0.035 & -0.018 & 0.000131 \\
\hline
\end{tabular}

A close perusal of Table 3 reveals that for all binary mixtures these mixing rules show a good agreement. In all selected systems, refractive index values predicted by Heller has shown excellent agreement with experimental values followed by Lorentz-Lorenz and Eyring-John relation, which gives fairly good results, where deviations from theoretical values are more in case of Weiner relation. Heller relation has performed well in case of all binary systems because the variation and deviation with concentration is monotonic without a maximum and with a change in sign. The deviations are within negative values in all the nine rules so studied. In general for binary systems, the deviations are found to be negative where dispersion and dipolar interactions are operating. It is suggested that deviation of theoretical values from experimental values can be reduced if excess volumes is taken into consideration. So the small negative deviations can be accounted for the volume deviation without consideration that there is no change in molecular polarizability on mixing of the components.

Deviations are significant up to three digits of decimal in all the nine rules so studied. The system can be considered to be nearly ideal one for the test of various other mixing rules. The Average Deviation value for all the systems ranges from -0.004586 to -0.008183 . Since liquids of different nature, which has significant difference in molecular size are considered, a particular relation provides excellent agreement at some places and deviates at others. The observed deviations are expected and can be ascribed to the volume additivity. As during mixing, excess volume is the measurement of molecular interaction in liquid mixtures. The structural property of liquid and liquid mixtures can be integrated through refractive indexes employing molar refraction. Molar refractions for the selected binary mixtures of eucalyptol with hydrocarbons are in the following order. 
Table 3. Average deviations* in the Refractive Index from different mixing relations for Eucalyptol + Hydrocarbon binary mixtures at $303.15 \mathrm{~K}, 308.15 \mathrm{~K}$ and $313.15 \mathrm{~K}$

\begin{tabular}{ccccccccccc}
\hline \multicolumn{1}{c}{ Eucalyptol $\left(\mathrm{x}_{1}\right)+o$-Xylene $\left(\mathrm{x}_{2}\right)$} & \multicolumn{2}{c}{ Eucalyptol $\left(\mathrm{x}_{1}\right)+m$-Xylene $\left(\mathrm{x}_{2}\right)$} & \multicolumn{4}{c}{ Eucalyptol $\left(\mathrm{x}_{1}\right)+$ Toluene $\left(\mathrm{x}_{2}\right)$} \\
\hline Mixing & & & & & & & & & & \\
Rules & $303.15 \mathrm{~K}$ & $308.15 \mathrm{~K}$ & $313.15 \mathrm{~K}$ & $303.15 \mathrm{~K}$ & $308.15 \mathrm{~K}$ & $313.15 \mathrm{~K}$ & $303.15 \mathrm{~K}$ & $308.15 \mathrm{~K}$ & $313.15 \mathrm{~K}$ \\
\hline A-B & -0.006008 & -0.006796 & -0.007120 & -0.004680 & -0.005711 & -0.006720 & -0.005169 & -0.005954 & -0.006666 \\
G-D & -0.006008 & -0.006796 & -0.007120 & -0.004680 & -0.005711 & -0.006720 & -0.005169 & -0.005954 & -0.006666 \\
L-L & -0.005882 & -0.006667 & -0.006987 & -0.004593 & -0.005621 & -0.006627 & -0.005087 & -0.005873 & -0.006591 \\
W & -0.007022 & -0.007832 & -0.008183 & -0.005376 & -0.006437 & -0.007468 & -0.005825 & -0.006604 & -0.007273 \\
H & -0.005871 & -0.006655 & -0.006976 & -0.004586 & -0.005614 & -0.006619 & -0.005081 & -0.005867 & -0.006585 \\
Nw & -0.006125 & -0.006915 & -0.007242 & -0.004760 & -0.005795 & -0.006806 & -0.005245 & -0.006029 & -0.006736 \\
E-J & -0.005950 & -0.006736 & -0.007059 & -0.004640 & -0.005670 & -0.006677 & -0.005131 & -0.005917 & -0.006631 \\
Eyk & -0.005973 & -0.006760 & -0.007082 & -0.004655 & -0.005686 & -0.006694 & -0.005146 & -0.005931 & -0.006645 \\
Os & -0.006081 & -0.006869 & -0.007195 & -0.004729 & -0.005763 & -0.006773 & -0.005215 & -0.006000 & -0.006709 \\
\hline
\end{tabular}

- $\quad\left[\left(\mathrm{n}_{\text {obsd. }}-\mathrm{n}_{\text {calcd. }}\right) / \mathrm{n}\right]$ 


\section{Toluene $<o$-Xylene $<m$-Xylene}

In general molar refraction increases with molecular weight for symmetric and asymmetric molecules. Density and refractive index depend on molecular weight and nature of solution. Density and refractive index values decrease with increase of temperature from $303.15 \mathrm{~K}$ to $313.15 \mathrm{~K}$.

For all the three binary mixtures, Weiner relation has exhibited deviation higher in value than Heller, Eyring-John and Eykman relations at all temperatures. It should be noted that the calculated average deviation values between the Arago-Biot and Gladstone-Dale relations are exactly same for all systems at all temperatures. This is expected because of similarities in the functional forms of these equations; as per literature ${ }^{21}$. Gladstone-Dale relation is more frequently used than the Arago-Biot equation. However, most generally, the Heller relation gives the least deviation in value as compared to other mixing rules.

\section{Conclusions}

All nine mixing rules could be successfully applied at lower concentration of eucalyptol omitting other factors such as volume reduction, volume addition and temperature. Weiner equation could not give better results. All nine theoretical mixing rules performed well within the limits of experimental error. The deviation between theoretical and observed values of refractive indexes for all system taken under consideration can be reduced if the concept of excess molar volumes is taken into consideration. Results from Redlich-Kister polynomial equation reveal that strong intermolecular interactions related to decrease in molar volume and negative enthalpy change takes place on mixing.

\section{References}

1 Arago D F J and Biot J B, Mem. Acad. Fr. 1806, 7.

2 Gladstone F and Dale D, Philos. Trans. R. Soc. 1858, 148, 887.

3 Lorentz H A, Weid. Ann. 1880, 9, 641.

$4 \quad$ Lorenz L Weid. Ann. 1880, 11, 70.

5 Bottcher C J F,Theory of Electric Polarization, Elsevier, Amsterdam, 1952.

6 Weiner O, Leipz. Ber. 1910, 62, 256.

7 Heller W, Phys. Rev. 1945, 68, 5.

$8 \quad$ Kurtz S S and Ward A L J, Franklin Inst. 1936, 222, 563.

9 Oster G, Chem. Rev. 1948, 43, 319.

10 Eyring H and John M S, Significant liquid structures, John Wiley, New York, 1969.

11 Lal K, Tripathi N and Dubey G P, J. Chem. Eng. Data 2000, 45, 961.

12 Pal A and Kumar A, J. Chem. Eng. Data 1998, 43, 143.

13 Pineiro A, Brokos P, Amigo A, Pintos M and Bravo R, J. Chem. Thermodyn. 1999, 31, 931.

14 Aminabhavi T M and Banerjee K, J. Chem. Eng. Data 1998, 43, 509.

15 Page M and Jolicoeur C, J. Chem. Thermodyn. 1993, 25, 139.

16 Sakurai M, J. Chem. Eng. Data, 1992, 37, 492.

17 Gomaa E, Indian J. Technol. 1988, 26, 461.

18 Rao M V P, Venkatesu P and Venkatesulu D, J. Chem. Eng. Data 1994, 39, 140.

19 Singh K C, Kalara K C and Kumar P, Indian J. Chem. 1990, 29, 124.

20 Redlich O and Kister A T, Ind. Eng. Chem. 1948, 40, 345.

21 Aminabhavi T M, Phayde H T S and R S Khinnavar R S, J. Chem. Eng. Data 1994, 39, 251.

22 Armarego W L F and Perrin D D, Purification of Laboratory Chemicals, $4^{\text {th }}$ Ed., Butterworths, Oxford, 1996. 


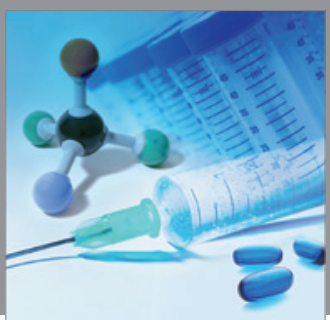

International Journal of

Medicinal Chemistry

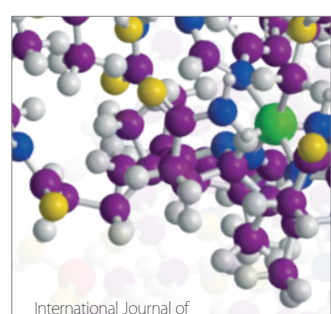

Carbohydrate Chemistry

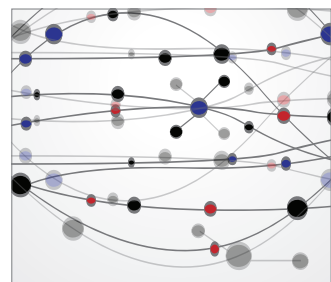

The Scientific World Journal
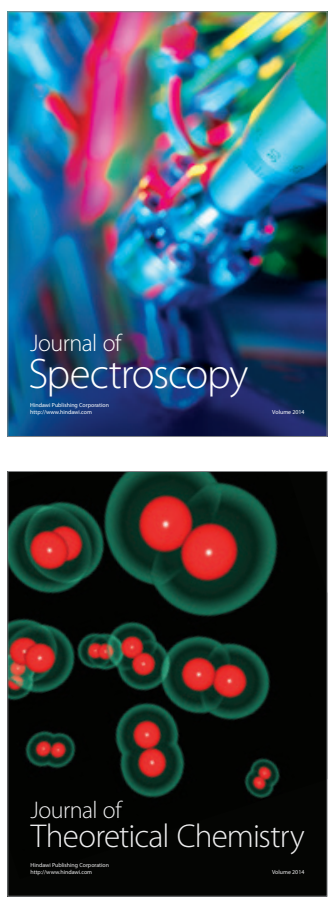
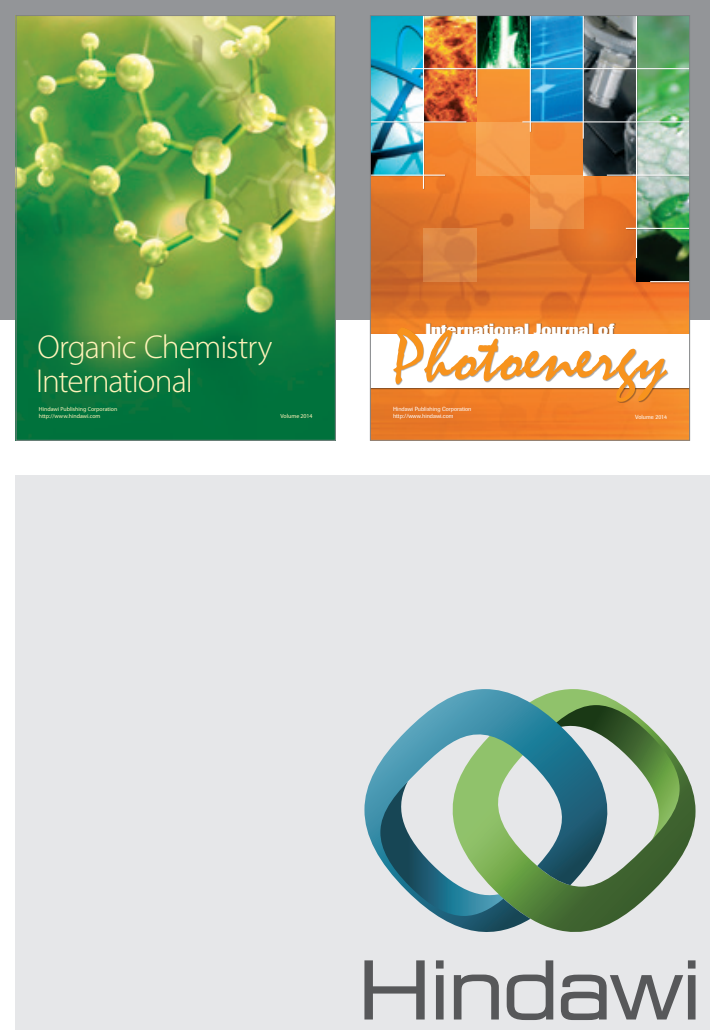

Submit your manuscripts at

http://www.hindawi.com
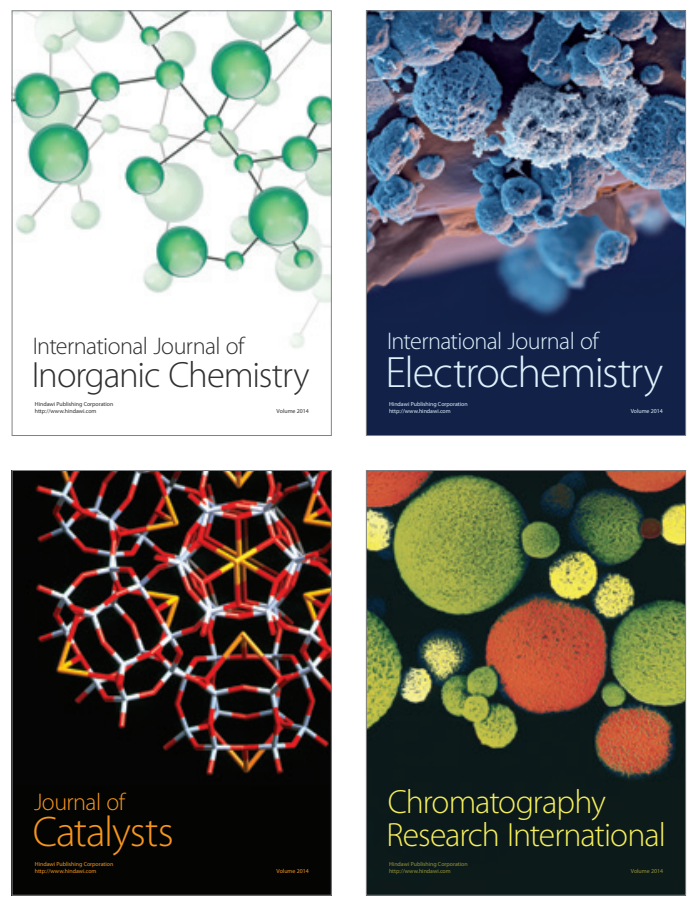
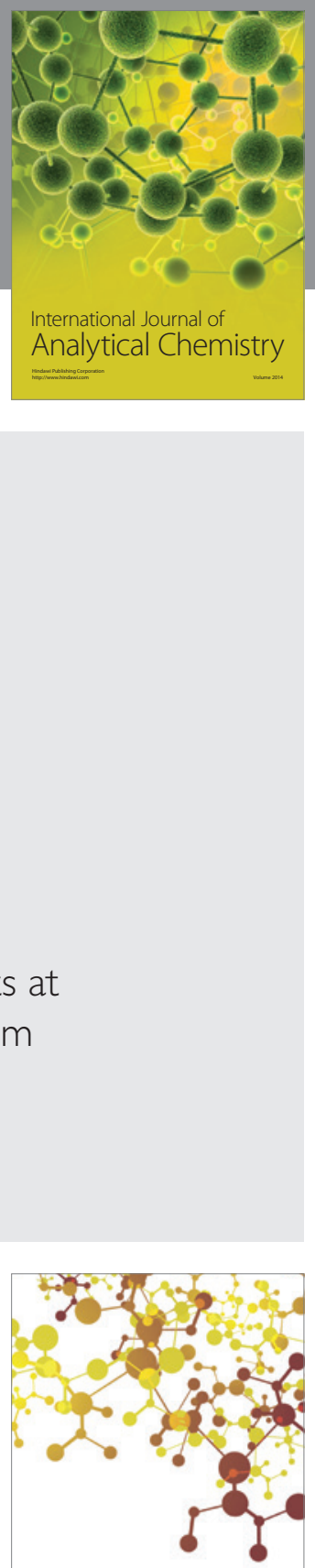

Journal of

Applied Chemistry
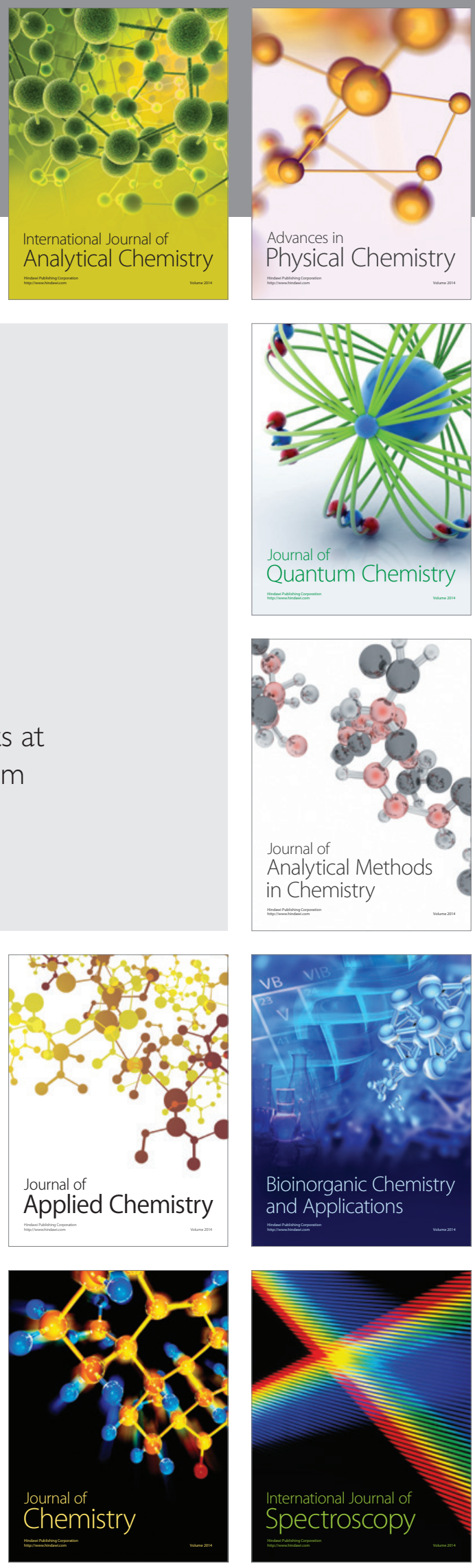